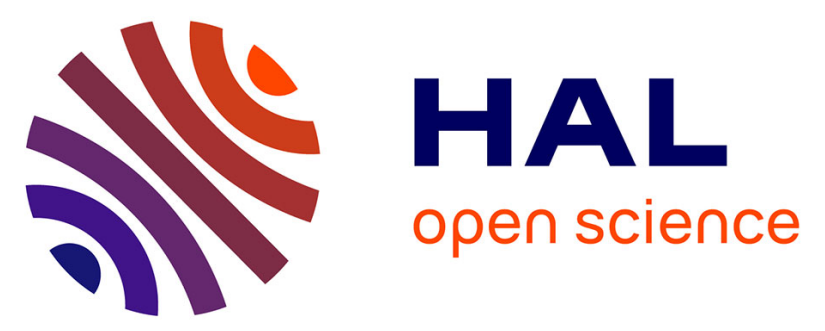

\title{
Surface-enhanced Raman scattering from semiconductor and graphene quantum dots coupled to metallic-film-on-nanosphere substrates
}

Pham Nam Thang, Le Xuan Hung, Dao Nguyen Thuan, Nguyen Thu Loan, Guillaume Binard, Willy Daney de Marcillac, Agnès Maître, Nguyen Quang Liem, Laurent Coolen, Pham Thu Nga

\section{To cite this version:}

Pham Nam Thang, Le Xuan Hung, Dao Nguyen Thuan, Nguyen Thu Loan, Guillaume Binard, et al.. Surface-enhanced Raman scattering from semiconductor and graphene quantum dots coupled to metallic-film-on-nanosphere substrates. Applied physics. A, Materials science \& processing, 2019, 125 (5), pp.337. 10.1007/s00339-019-2641-6 . hal-02492394

\section{HAL Id: hal-02492394 https://hal.science/hal-02492394}

Submitted on 26 Feb 2020

HAL is a multi-disciplinary open access archive for the deposit and dissemination of scientific research documents, whether they are published or not. The documents may come from teaching and research institutions in France or abroad, or from public or private research centers.
L'archive ouverte pluridisciplinaire HAL, est destinée au dépôt et à la diffusion de documents scientifiques de niveau recherche, publiés ou non, émanant des établissements d'enseignement et de recherche français ou étrangers, des laboratoires publics ou privés. 


\title{
Surface-enhanced Raman scattering from semiconductor and graphene quantum dots coupled to metallic-film-on- nanosphere substrates
}

\author{
Pham Nam Thang ${ }^{1,2}$, Le Xuan Hung ${ }^{3}$, Dao Nguyen Thuan ${ }^{1}$, Nguyen Thu Loan ${ }^{1}$, \\ Guillaume Binard ${ }^{4}$, Willy Daney de Marcillac ${ }^{4}$, Agnès Maître ${ }^{4}$, \\ Nguyen Quang Liem ${ }^{1}$, Laurent Coolen ${ }^{4}$, Pham Thu Nga ${ }^{3,1,2^{*}}$ \\ ${ }^{1}$ Institute of Materials Science, Vietnam Academy of Science and Technology, \\ 18 Hoang Quoc Viet Road, Cau giay Dist., Hanoi, Vietnam \\ ${ }^{2}$ Graduate University of Science and Technology, Vietnam Academy of Science and \\ Technology \\ 18 Hoang Quoc Viet Road, Cau giay Dist., Hanoi, Vietnam \\ ${ }^{3}$ Institute of Theoretical and Applied Research, Duy Tan University, Vietnam \\ ${ }^{4}$ Sorbonne Universités, UPMC Univ Paris 06, UMR 7588, Institut de NanoSciences de Paris \\ (INSP), Paris F-75005, France
}

\begin{abstract}
In this article, we perform surface-enhanced Raman scattering (SERS) with a periodically corrugated metallic substrate obtained by evaporating an Ag film onto an artificial opal crystal, which is a self-assembled lattice of $\mathrm{SiO}_{2} 600$-nm spheres. These metallic-film-on-nanosphere (MFON) surfaces are characterized by scanning electron microscopy for different Ag film thicknesses ranging from 44 to $620 \mathrm{~nm}$. Raman scattering spectra are measured for two different types of quantum dots, CdTeSe quantum dots (QDs) and graphene quantum dots (GQDs). We are able to show that enhancement of the Raman spectra can be obtained for all MFON substrates and for both types of QDs. For both CdTeSe and graphene quantum dots, the strongest SERS effect was observed in samples with $135 \mathrm{~nm}$ Ag thickness. This is attributed to the formation of hot spots in the nanogap dips of the Ag film.
\end{abstract}

Keywords: $\mathrm{SiO}_{2}$ spheres, opal, Ag plasmonic films, CdTeSe quantum dots, graphene quantum dots GQDs, Raman spectra, SERS.

\section{Introduction}

Colloidal quantum dots (QDs) have been the subject of a vast range of fundamental and applied studies. Various compositions were considered in order to tune their emission wavelength, including ternary alloyed QDs such as CdTeSe whose emission is in the red to near-infrared region [1-7], with applications in biosensing, displays, and potential future developments in solar cells, lighting, opto-electronics or quantum optics. More recently, graphene quantum dots (GQDs) have been synthetized. They are small graphene fragments (less than $20 \mathrm{~nm}$ in size), in which electron transport is confined in all three dimensions. GQDs combine the unique photoelectronic properties attributed to quantum confinement effects [8,9] and edge effects [10-12]. They are considered for applications in solar energy, photocatalysts, biosensors, bioimaging, drug delivery, photovoltaic and biomedical devices thanks to their bright and stable emission and good biological compatibility [13-19].

Photoluminescence is most generally used to detect QDs due to its great sensitivity. Luminescence from small amounts of QDs can easily be detected, even down to the singleemitter level when the quantum yield is sufficient. Raman spectroscopy provides less sensitivity because of its much smaller cross-section, but it offers a wealth of information about the QD's vibrational properties which is not accessible by other methods. The frequency of a phonon's Raman peak can be related to the QD's size and shape as well as to its internal strain or to its chemical composition or surface state. Raman spectroscopy can thus be used to analyze QDs and guide their synthesis, to study the vibrational properties in connection with relaxation mechanisms, or for multiplexed detection of biomarkers of different compositions. For instance, for alloyed QDs, the Raman spectra can be related to the concentration of the various 
components of the alloy [1]. For GQDs, Raman spectroscopy can be used to demonstrate the formation of the quantum dots.

When Raman intensity is too low to be detected, surface-enhanced Raman spectroscopy (SERS) can be used: the nanoparticles are deposited on a metallic film such as $\mathrm{Au}, \mathrm{Ag}$ or $\mathrm{Al}$ : these films present surface plasmon modes at the air-metal interface with strongly confined electromagnetic fields which can favor light emission and absorption. SERS can be used for chemical analysis, detection of pollutants or bacterias, photochemical studies or vibrational spectroscopy [20] down to the single-emitter level [21, 22]. The search for efficient and unexpensive SERS metallic substrates is a very active field and many different substrates and fabrication methods have been proposed, as exemplified most recently by $\mathrm{Au}$ nanoparticles obtained by femtosecond exposure of a Au film [23], by bipyramid Au nanoparticles [24], by Ag-nanoparticles growth on Si by replacement method [25] or by stripes of vertical or horizontal Au nanorods [26]. The key element is the presence of sharp tips or dips on the surface of the metallic substrate, where plasmonic modes can be strongly confined and create "hot spots”. Hot spots are also essential to future applications of plasmonics in photochemistry or photovoltaics [20]. A few papers have applied SERS to QDs of different materials : CdS [27], CdSe [28-30], $\mathrm{PbS}$ [31], $\mathrm{SnO}_{2}$ [32] or Si [33]. SERS is a promising technique for QD detection and may be applied for the detection of traces of nanoparticles, for the detection of biomarkers or for in-situ tracking of the nanoparticles'surface chemical properties such as their oxidation [31, 33]. SERS has also allowed phonon modes analysis of single CdSe nanoplatelets [34].

Deposition of "metallic film on nanosphere" (MFON) samples has emerged as a convenient and reproducible way to produce a corrugated metallic surface for SERS analysis [35, 36]. These samples are obtained by evaporating a metallic layer on top of an ordered self-organized array of polymer or silica nanospheres. SERS enhancement factors in the range from $10^{3}$ to $10^{11}$ have been reported [20]. Promising SERS measurements have been performed with dye molecules on MFON substrates [37-39] as reviewed in [20] and applications have been demonstrated for DNA detection [40], ricine [41] or anthrax [42] sensing, or tracking of alumina atomic layer deposition [43]. However, to our knowledge, no SERS study on QDs have used MFON substrates - although a few groups have considered QD photoluminescence enhancement by MFON [44, 45].

In this paper, we use MFON substrates for SERS characterization of different types of QDs. We start the paper with a precise structural characterization of the sample fabrication steps: silica spheres synthesis, self-assembled deposition of the spheres into a three-dimension lattice (opal), and Ag layer deposition with various thicknesses considered. We then analyze the SERS spectra on the different substrates for two types of quantum dots: CdTeSe QDs and GQDs. We show that SERS can be obtained with both types of QDs for all substrates, discuss the measured SERS enhancement factor and identify the best Ag thickness.

\section{Experimental}

\subsection{Preparation of $\mathrm{SiO}_{2}$ spheres and fabrication of opal films on glass substrate}

We have synthesized $\mathrm{SiO}_{2}$ spheres in absolute ethanol solvent based on W. Stoeber's method [46]. However, we have made improvements to the fabrication method and used high-grade purity 1,4-dioxane as organic solvents to obtain large $600 \mathrm{~nm} \mathrm{SiO} 2$ spheres with narrow size distribution, as suggested in [47]. Tetraethyl orthosilicate (TEOS) 98\% purchased from SigmaAldrich has been used as the silica precursor. Absolute ethanol and 1,4-dioxane 99.8\% have been used as a solvent. The desired $\mathrm{pH}$ of approximately 10 was controlled by adding dilute ammonia to distilled water.

The typical synthesis process that we used is as follows: $20 \mathrm{ml}$ of tetraethyl orthosilicate (TEOS) was dissolved in a mixture of $160 \mathrm{ml}$ absolute ethanol and 40ml 1,4-dioxane with magnetic stirring at room temperature. After a 20-minute equilibration, a dilute solution of 15 $\mathrm{ml} 25 \% \mathrm{NH}_{4} \mathrm{OH}$ in $50 \mathrm{ml} \mathrm{H}_{2} \mathrm{O}$ was added to the solution so that $\mathrm{pH}=10$. After 5 minutes, the solution turned white revealing the formation of $\mathrm{SiO}_{2}$ nanospheres, then became opaque white. 
This reaction lasted 24 hours and the $\mathrm{SiO}_{2}$ spheres increased up to a size close to $350 \mathrm{~nm}$. After one day, the size of the $\mathrm{SiO}_{2}$ nanospheres was controlled by adding $10 \mathrm{ml}$ TEOS after each 2hour period and observing SEM images during the spheres' growth process. For $600 \mathrm{~nm}$ spheres, six steps of TEOS addition (or a total amount of $80 \mathrm{ml}$ TEOS) were necessary for a complete growth process. When $\mathrm{SiO}_{2}$ spheres reached the average size of $600 \mathrm{~nm}$, an amount of $200 \mathrm{ml}$ absolute ethanol was added, then stirred again for $8 \mathrm{~h}$ to obtain stable sol. Finally, the resulting white sol was diluted again in $300 \mathrm{ml}$ ethanol and stored in a polyethylene bottle for sedimentation of $\mathrm{SiO}_{2}$ spheres.

The white sedimentation was washed with absolute ethanol by centrifuging at $1200 \mathrm{rpm}$ for 3 minutes to obtain $\mathrm{SiO}_{2}$ spheres. The washing process was repeated five times in order to remove the impurities completely. The obtained opaque white $\mathrm{SiO}_{2}$ spheres with an average size of 600 $\mathrm{nm}$ were dispersed again in absolute ethanol or dried for the next experiments.

A three-dimension dielectric lattice can be obtained by self- organization of the silica spheres, leading to artificial opal samples. The preparation of opal films has been carried out as described in our previous paper [48]: a silica glass substrate was placed in a transparent cup at a 30 degree angle to the cup wall. This cup contained the suspensions of suitable $\mathrm{SiO}_{2}$ concentrations (up to $10 \mathrm{wt} \%$ ) in absolute ethanol. In order to obtain a high-quality regular assembly of the $\mathrm{SiO}_{2}$ spheres by self-organization at the meniscus, the ethanol was evaporated very slowly at $30^{\circ} \mathrm{C}$. The colloidal opal crystals then dried naturally at room temperature.

\subsection{Deposition of the Ag film on the opal ordered template}

Silver and gold are the most prominent metals for plasmonic samples in the visible range. Gold provides a better stability but its ohmic losses are higher, especially in the blue-green range which is considered in the present SERS measurements. For this reason, we used silver for the design of our MFON samples.

Ag films were obtained by evaporating a Ag layer on a self-assembled opal, with a different Ag thickness for each sample. The Ag layers were deposited onto the opal by thermal evaporation using a VHD-30 system. The deposition process was carried out at a pressure of $10^{-5}$ torr. The substrates were kept at room temperature and the distance from the evaporation source to the substrates was $20 \mathrm{~cm}$. The thickness of the Ag layer was monitored and controlled using a quartz oscillator system. Ag layers were evaporated with various thicknesses.

A structural characterization of the MFON substrates was carried out by field emission scanning electron microscopy (FE-SEM) (S4800-Hitachi) to determine the size of the $\mathrm{SiO}_{2}$ spheres, the morphology of the opal samples and check the Ag layer thickness. The Ag layer thickness was estimated from the SEM images as the height at the top of the spheres subtracted by the spheres diameter. The obtained Ag thicknesses ranged from 44 to $620 \mathrm{~nm}$.

\subsection{SERS measurements}

The CdTeSe QDs samples used in this study, of diameter $6.3 \mathrm{~nm}$, were fabricated by the method published in [1], and the GQDs samples by the one published in [49, 50]. The CdTeSe QDs have an emission at $735 \mathrm{~nm}$ and an absorption at $700 \mathrm{~nm}$. The GQDs are disks of diameter 25 $\pm 10 \mathrm{~nm}$ with an absorption peak at $350 \mathrm{~nm}$ and an emission peak at $470 \mathrm{~nm}$.

A 12- $\mu \mathrm{L}$ droplet of the QD solution (either CdTeSe QD or GQD) was deposited onto each MFON substrate, forming for all samples a disk of around 4-mm diameter. The Raman spectra were analyzed by Micro Raman spectroscopy (XploRA- Horiba) using the $532 \mathrm{~nm}$ (25 mW) excitation line from a diode-pumped, solid state laser to analyze the vibration bonds and their Raman frequencies. The laser power was $0.25 \mathrm{~mW}$. A x10 objective was used to focus the excitation laser light onto the investigated samples. The size of the excitation laser spot on the sample was $1 \mu \mathrm{m}$. The spectral resolution was $2 \mathrm{~cm}^{-1}$. The acquisition time was $10 \mathrm{~s}$. The system uses a Charge Coupled Device (CCD) receiver with with four gratings 600, 1200, 1800 and 
$2400 \mathrm{gr} . / \mathrm{mm}$, measuring from 100 to $4000 \mathrm{~cm}^{-1}$. In this work, we have used a $1200 \mathrm{gr} . / \mathrm{mm}$ grating. The Raman spectra were compared with the reference Raman spectra measured on a glass substrate with a QD droplet deposited under the same conditions.

\section{Results and discussion}

\section{1. $\mathrm{SiO}_{2}$ spheres and opal samples preparation}

SEM images recorded at each growth stage of the $\mathrm{SiO}_{2}$ spheres have allowed us to determine the size and growth kinetics of the $\mathrm{SiO}_{2}$ spheres. The number of fabricated spheres will depend on the number of initial seeds created when starting the reaction. These seeds are controlled by the concentration of the source precursor that created the $\mathrm{SiO}_{2}$, which is the amount of TEOS brought into the initial reaction compared to absolute ethanol, and the speed at which the reacting solution is stirred. When stirring the solution, the chemical reactions will happen until the initial TEOS is depleted. At this moment, we add the same amount of TEOS to the solution, to supply Si creating $\mathrm{Si}-\mathrm{O}$ links with those on the surface of $\mathrm{SiO}_{2}$ spheres. These spheres keep developing in this growth process and every time TEOS is depleted, we add another amount into the mixture, until the desired sphere size is reached, up to $600 \mathrm{~nm}$. For spheres sized 600 $\mathrm{nm}$, we used 1,4-dioxane as the solvent for the growth process. Figure 1 shows the SEM images of the $600-\mathrm{nm} \mathrm{SiO}_{2}$ spheres (left) and the surface image of the opal sample (right). A good ordering of the silica spheres in the opal is obtained, as will be confirmed by more surface and lateral SEM images in the next figures.

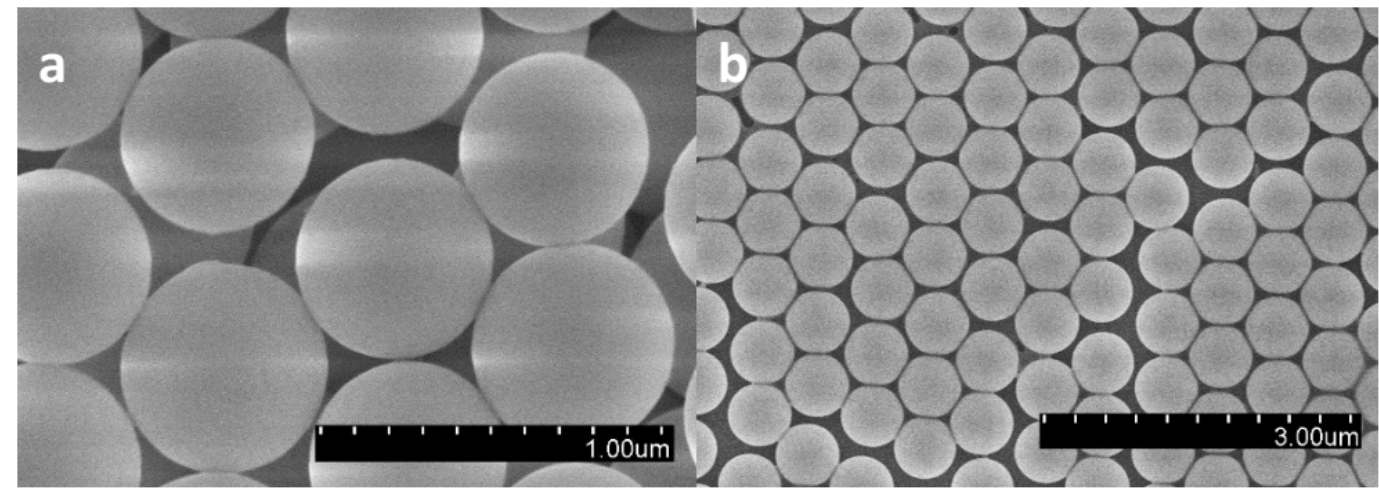

Figure 1. SEM images of synthesized $\mathrm{SiO}_{2}$ spheres with the size $600 \mathrm{~nm}$ (left), and of the surface of an opal sample (right).

\subsection{Structural and optical properties of the MFON substrates}

The MFON samples have been studied by SEM. Figure 2 a shows SEM images of a first Agcovered opal sample, with Ag-film thickness of only $5 \mathrm{~nm}$. We can see that the Ag deposition forms small islands on top of the silica spheres. The amount of Ag is not sufficient to coalesce and produce a uniform film. However, for the sample in which $44 \mathrm{~nm}$ Ag is evaporated, the percolation threshold is reached and the evaporated Ag covers the opal surface. For instance, fig. $2 \mathrm{~b}$ shows the surface topography of the $135 \mathrm{~nm}$ sample, for which the continuous deposition of the Ag layer appears clearly. 


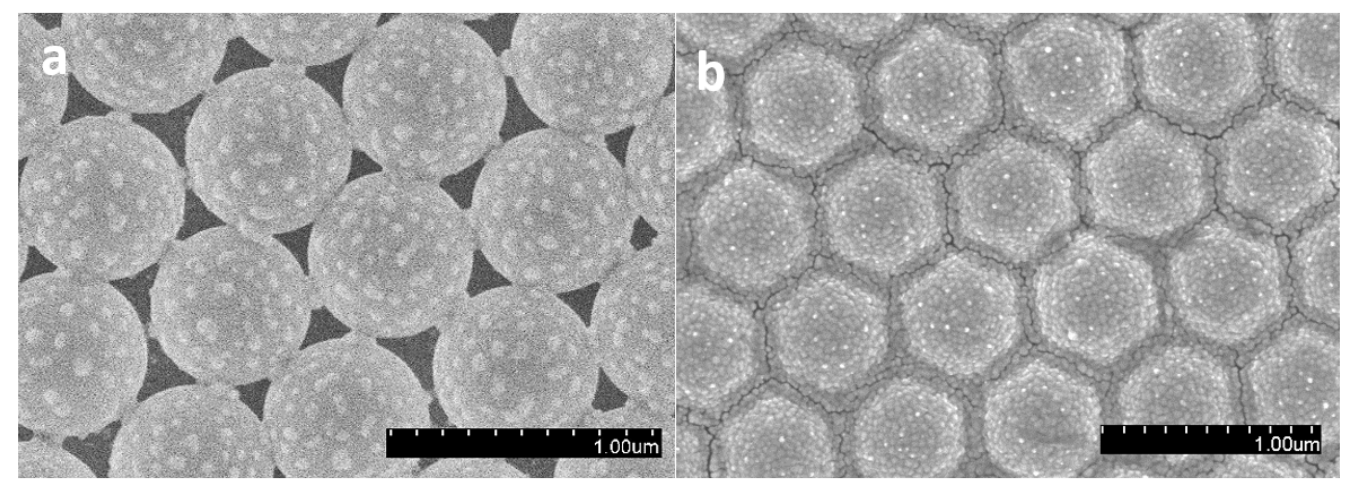

Figure 2. SEM images of opal samples coated with a $5 \mathrm{~nm}$ (a) and a 135-nm (b) thick Ag layer.

Figure 3 shows cross-section SEM images of the different obtained MFON samples for Ag thickness of $44 \mathrm{~nm}$ and above. These SEM images show that the Ag film completely covers the upper half of the silica spheres and creates a continuous corrugated metallic surface.

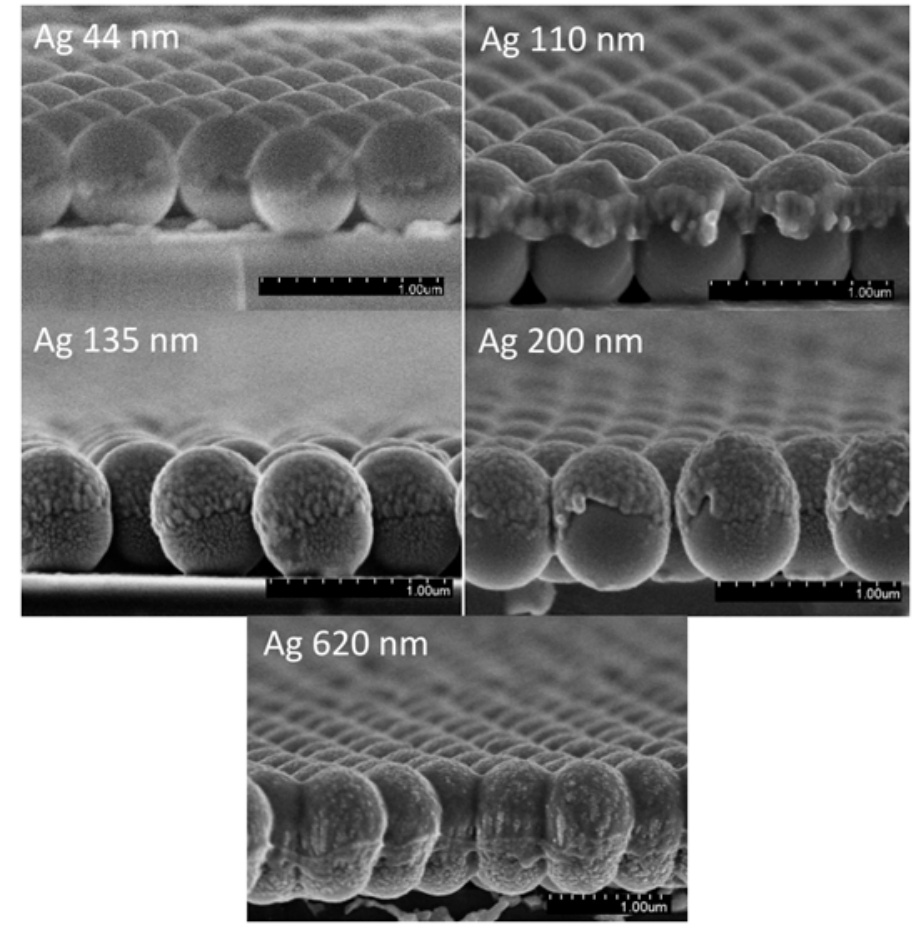

Figure 3. SEM images of Ag-coated opal samples with different thickness: 44, 110, 135, 200, and $620 \mathrm{~nm}$.

We can measure on the SEM images the corrugation depth, which we define as the height difference between the upper and lower points of an Ag film surface profile [36]. Table 1 reports the value of the corrugation depth for each sample of different Ag thickness. For the lowest Ag thickness (44 nm), the corrugation depth is highest at $220 \mathrm{~nm}$ : in this case the Ag film profile follows approximately the profile of the silica spheres, which has a $300-\mathrm{nm}$ depth (as the spheres have 600-nm diameter).On the other hand, for the highest Ag thickness, the MFON surface is mostly smoothed as the deposited Ag fills the space between the spheres, and the corrugation depth is now only $110 \mathrm{~nm}$ for a 620 Ag layer. A similar behavior can be observed for Au deposition on an opal [36]. However, here the evolution of the corrugation depth as a function of the deposited Ag thickness is not monotonous as there is a competition between $\mathrm{Ag}$ deposition into the gaps between the spheres and deposition on the top of the spheres, the latter 
being often favored due to shadowing effects. Further smoothing might be obtained by addition of a silica sub-layer [36].

Table 1. The depth of the MFON profile corrugation (average difference between the upper and lower points of the sample profile) for each deposited Ag thickness

\begin{tabular}{cccccc}
\hline Ag thickness (nm) & 44 & 110 & 135 & 200 & 620 \\
Corrugation depth $(\mathrm{nm})$ & 220 & 110 & 170 & 180 & 110 \\
\hline
\end{tabular}

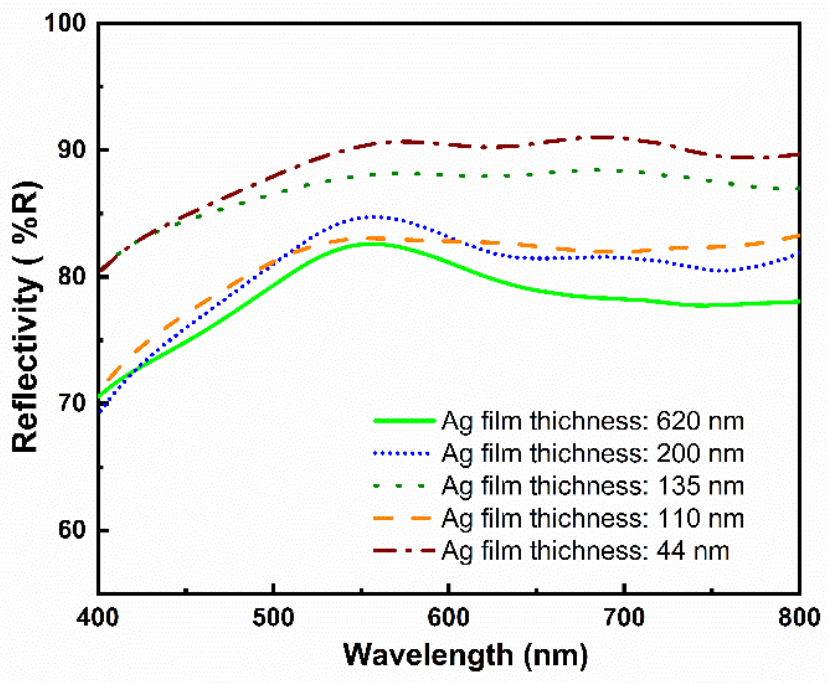

Figure 4. Reflection spectra of the MFON substrates.

Figure 4 plots the reflection spectrum of each sample. The reflectivity for all samples is in the range $70-90 \%$. It is lower than for a planar Ag layer, as observed previously for Au MFONs [44]. This loss in specular reflectivity includes scattering effects by the corrugated surface as well as absorption by localized surface plasmon (LSP) modes. The spectra present a flat "plateau" profile above $500 \mathrm{~nm}$ similar to the reflection spectra of random gold patterns [51], which was attributed by the authors to localized surface plasmon (LSP) modes. The continuum of LSP frequencies in ref. 51 was explained and successfully modelled by the broad range of "hot spot" sizes and geometries present in the random fractal gold film [52]. The self-assembly fabrication process for MFONs thus seems to produce a diverse range of hot spot geometries leading to a continuum of LSP frequencies. This also offers a broad choice of excitation wavelengths for SERS experiments.

\subsection{SERS study of the quantum dots}

CdTeSe QDs and GQDs were deposited onto the Ag film surface. 


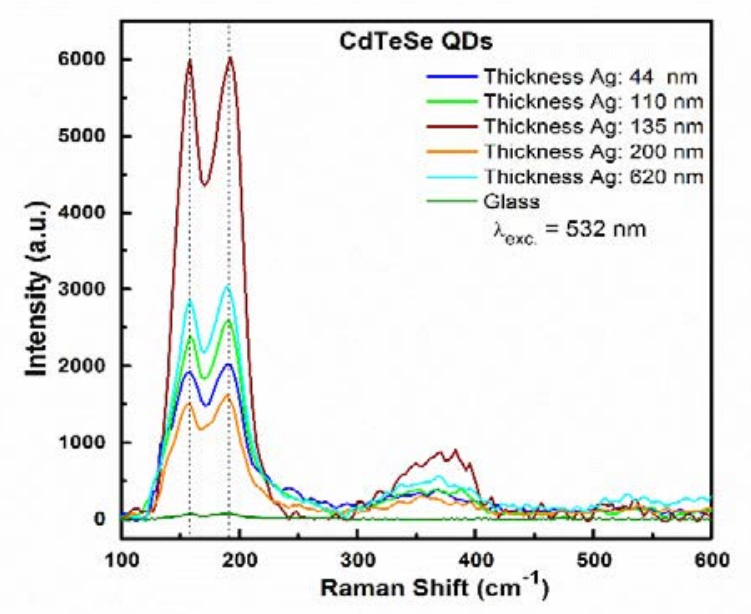

Figure 5. Raman scattering spectra of the CdTeSe QDs on the MFON substrates with various Ag thicknesses, from $44 \mathrm{~nm}$ to $620 \mathrm{~nm}$, and on a glass substrate. The excitation wavelength is $532 \mathrm{~nm}$.

Figure 5 shows the Raman spectra of the CdTeSe QDs on different Ag thicknesses, compared to the Raman spectrum of these QDs residing on glass. The obtained spectra present a double line as usually seen in alloy QDs and characteristic of the two vibration lines of the CdTe-like LO phonon line and the CdSe-like LO phonon line residing respectively at $159 \mathrm{~cm}^{-1}$ and 192 $\mathrm{cm}^{-1}$. These Raman spectral lines are in complete agreement with the published vibration lines of CdTeSe $[1,53,54]$. The positions of these two Raman spectral lines are unchanged compared to QDs on glass, but their intensity is much higher for the MFON samples.

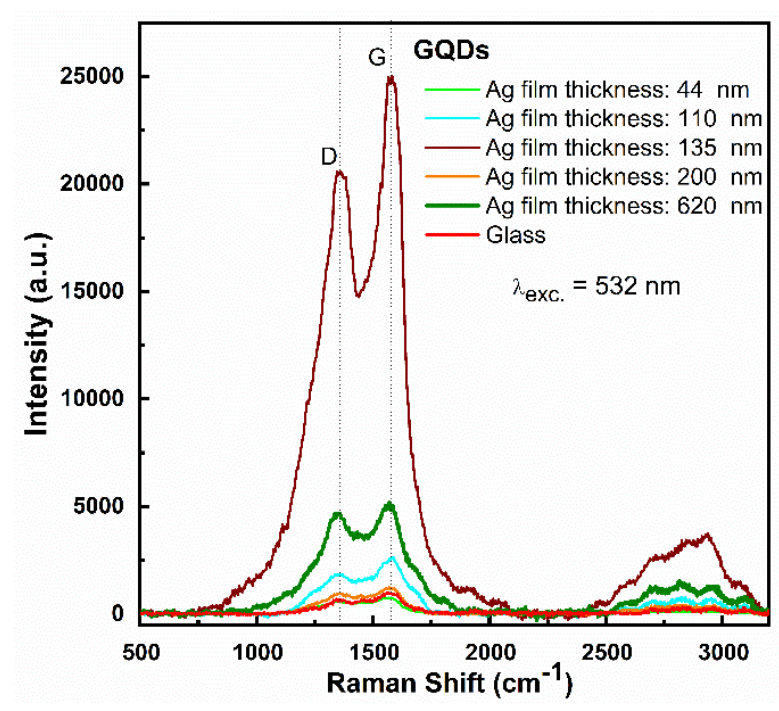

Figure 6. Raman scattering spectra of GQDs on MFON substrates with Ag thicknesses from $44 \mathrm{~nm}$ to $620 \mathrm{~nm}$, and on a glass substrate. The excitation wavelength is $532 \mathrm{~nm}$.

We also used our MFON substrates to analyze graphene quantum dots. Raman spectroscopy is the most familiar tool to identify the formation of GQDs. Fig. 6 shows the Raman spectra of GQDs with various Ag film thicknesses, along with the Raman spectrum of these GQDs on glass. Two peaks are observed at 1361 and $1575 \mathrm{~cm}^{-1}$ (and their second-order replicas appear between 2500 and $3000 \mathrm{~cm}^{-1}$ ). The peak at $1575 \mathrm{~cm}^{-1}$ is assigned to the $\mathrm{G}$ peak, as observed in [16]. It corresponds to a first-order scattering process in graphene stemming from the doubledegenerate vibrational mode $\left(\mathrm{E}_{2 \mathrm{~g}}\right)$ at the crossing of the longitudinal optical $(\mathrm{LO})$ and transverse 
optical (TO) phonon bands at the $\Gamma$ point in the first Brillouin zone $[55,56]$. The peak at 1361 $\mathrm{cm}^{-1}$ is assigned to the D peak [56]. The D peak of the Raman spectrum comes from the "unorganized" carbon [56,57] which is associated with the defects or the edges of graphene. Both lines are strongly enhanced compared to the glass substrate.

There is thus a clear SERS effect for all MFON samples and for the two types of QDs. In order to quantify the improvement due to SERS, the SERS enhancement factor can be defined as the ratio between the Raman intensity per emitter on the substrate and the Raman intensity per emitter on the reference sample [20]. It must be noted that this standard definition of the SERS enhancement factor considers only the SERS intensity which is collected by the microscope objective and not the total SERS intensity. On a gold substrate, some light is reflected by the surface into the objective so that the collection efficiency can typically be expected to be better than on a glass substrate [58].The measured enhancement factor thus reflects the cumulated effects of the enhanced excitation field, the enhanced emission and the modified collection efficiency.

The number of emitters contributing to the SERS signal is usually estimated with some uncertainty and the homogeneity of the emitters deposition should be checked [20]. Here, we estimate the droplet deposition surface to be approximately the same (4 mm diameter) for all samples. The excitation laser spot is kept constant (around $1 \mu \mathrm{m}$ size) as well as the concentration of the CdTeSe and GQD solutions. We checked that the emitters distribution was uniform by measuring (fig. 7) the Raman spectrum on different locations of the sample for the CdTeSe (left) and graphene (right) QDs. The spectra over the deposited surface were approximately the same with identical emission lines and 5 to $10 \%$ differences in intensities for all samples, demonstrating the good uniform distribution on the sample, however with more dense deposition on the sides of the droplet. Eventually, the number of emitters involved in the Raman signal is assumed to be the same for all samples so that the enhancement factor is obtained as the ratio between the Raman intensity of the sample and the reference.
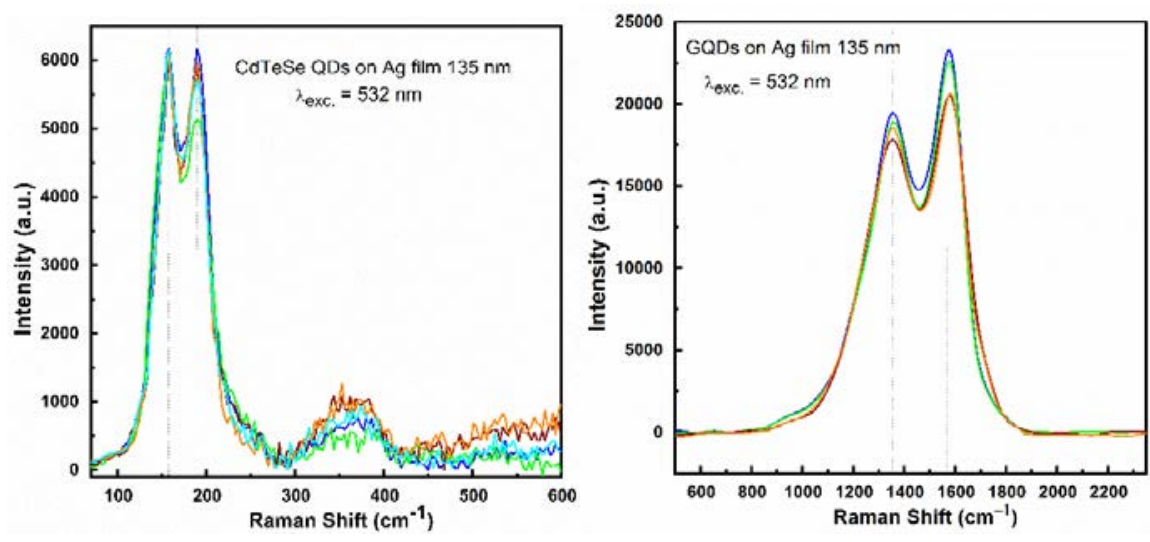

Figure 7. Raman scattering spectra of CdTeSe QDs (left) and GQDs (right) at different positions on the 135-nm-Ag MFON sample. The excitation wavelength is $532 \mathrm{~nm}$.

The obtained enhancement factors are listed in table 2. They range from 23 to 84 for the CdTeSe QDs and from 2 to 40 for the GQDs. It is remarkable that the maximal enhancement factor is obtained with the 135-nm-Ag sample for both types of QDs, while the 44-nm and 200-nm samples give minimal enhancement factors for both types of QDs. This appears as a sign that the different measured enhancement factors actually reveal plasmonic properties of the MFON samples, in spite of some uncertainty on the number of emitters, which can be common in SERS measurements as discussed in [20], and could appear here due to some deposition inhomogeneities. 
The differences in enhancement factors between the CdTeSe and graphene QDs may be explained by different photophysical properties as well as by the emitters occupying different positions on the MFON surface with respect to the hot spots, depending on their sizes, ligands.... The measured enhancement factors are much smaller than the typical $10^{8}$ ones reported for dye molecules on MFON substrates [20]. However, it should be noted that most of the few SERS studies on QDs did not report enhancement factor values. Only two publications reported enhancement factors of 40 to 700 for CdS QDs with Ag clusters [27] and 2000 for CdSe QDs with lithographic Au disks [30], both SERS studies being performed at excitation resonant with the plasmonic modes. Maximum values were obtained at $10^{4}$ by tip-enhanced Raman scattering (TERS) [30] and 5.10 ${ }^{4}$ enhancement with respect to a flat gold film for an emitter in a thin nano-gap between two gold surfaces [34]. There is thus a general tendency for lower SERS enhancement factors with QDs than with dye molecules, and our measurements show that the same substrate can lead to different enhancement factors depending on which type of QD is considered.

Table 2. Enhancement factor values of QDs Raman intensity for samples with different Ag film thicknesses

\begin{tabular}{ccccc}
\hline & \multicolumn{2}{c}{ CdTeSe QDs } & Graphene QDs \\
$\begin{array}{c}\text { MFON substrate Ag } \\
\text { thickness (nm) }\end{array}$ & $\begin{array}{c}\text { Raman } \\
\text { intensity } \\
\text { (a.u.) }\end{array}$ & $\begin{array}{c}\text { Enhancement } \\
\text { factor }\end{array}$ & $\begin{array}{c}\text { Raman } \\
\text { intensity } \\
\text { (a.u.) }\end{array}$ & $\begin{array}{c}\text { Enhancement } \\
\text { factor }\end{array}$ \\
\hline Glass reference & 72 & - & 600 & - \\
$44 \mathrm{~nm}$ & 2025 & 28 & 1116 & 2 \\
$110 \mathrm{~nm}$ & 2591 & 36 & 2616 & 4 \\
$135 \mathrm{~nm}$ & 6027 & 84 & 24004 & 40 \\
$200 \mathrm{~nm}$ & 1628 & 23 & 1147 & 2 \\
$620 \mathrm{~nm}$ & 3037 & 42 & 4837 & 8 \\
\hline
\end{tabular}

The nano-gaps at the junction between spheres are known to constitute hot spots which play an important role on SERS properties in these substrates [37]. Numerical simulations show that the electromagnetic field can be confined in these nano-gaps over distances of a few tens of nanometers [37, 38, 40]. The enhancement factor is thus expected to be related in particular to the corrugation profile and to be decreased when the profile is smoothed. However, the 44-nm Ag film has the highest corrugation depth but its enhancement factor is not the highest one. Refs [37] and [38] considered SERS of dye molecules on MFONs for different Ag thicknesses (but with smaller silica spheres: respectively 430 and $350 \mathrm{~nm}$ diameter). Both found an optimal Ag thickness for SERS, respectively at 40 and $150 \mathrm{~nm}$. The surface characteristics and the deposition conditions are probably important parameters which explain the different optimal thicknesses between the three experiments, ours and those of refs [37, 38]. The nanogap width is also a key parameter: it is generally smaller in ref. [37] than in [38], possibly explaining the higher enhancement factor in the former results. Ref. [39], on the other hand, used a 120-nm Ag layer and found that 1000-nm spheres provided the highest enhancement factor. The numerical simulations for these different reports yield quite different orders of magnitude for Ag MFON enhancement factors: ref. [37] estimates it from $3 \times 10^{5}$ to $1.5 \times 10^{6}$, while ref. [39] computes a maximum enhancement of 6000 (and ref. [40] finds $6 \times 10^{4}$ for Au MFONs). Some differences may be explained by the different metals (Au or Ag), thicknesses, sphere diameters and excitation wavelengths considered in the simulations. However the precise size and shape of the nano-gaps is probably also a key parameter (as demonstrated in ref. [37]) and is not easily probed experimentally. A clear general trend is that the orders of magnitude of the simulated 
enhancement factors are comparable with the measured ones for dye molecules [37] but much larger than the measured enhancements for QDs. These different results call for further studies on the different plasmonic coupling mechanisms for such samples. It has been shown that 25 $\%$ of the enhancement factors originates from the $0.01 \%$ of molecules which are at the most confined plasmonic hot spots [59]. Nevertheless localized surface plasmons are also known to couple to surface-plasmon-polaritons (SPP) modes propagating over the Ag surface [60] and SPPs are known to contribute to photoluminescence enhancement on MFON samples [44]. While the MFON SERS has been attributed to the plasmonic resonances and nanogaps between the spheres [37, 39], photo-emission electron microscopy (PEEM) has also shown the importance of hot spots at defects of the MFON surface [60].

\section{Conclusions}

We have fabricated $600 \mathrm{~nm} \mathrm{SiO}_{2}$ spheres which were used for the fabrication of opal crystals. By adding an Ag metal layer, a metallic-film-on-nanospheres (MFON) surface with 2D periodic corrugation structure was fabricated in order to create a plasmonic surface with hot spots enhancing the electromagnetic field. Raman spectroscopy studies on both CdTeSe QDs and GQDs deposited on MFONs was performed. Enhancement of SERS was observed for all samples and for both QDs, with maximum effect for the $135 \mathrm{~nm}$ Ag film. The Raman spectra intensity was then enhanced by $\sim 84$ times compared to when measured on glass substrate for CdTeSe QDs and 40 times for GQDs.

\section{Acknowledgments}

This research is possible thanks to PICS cooperation project (6456) between CNRS, INSPUPMC-VAST and funded by Vietnam National Foundation for Science and Technology Development (NAFOSTED) under grant number 103.03-2018.03. The authors thank the National Key Laboratory for Electronic Materials and Devices-IMS and Duy Tan University for the use of facilities.

\section{References}

[1] Hung LX, Bassène PD, Thang PN, Loan NT, Daney de Marcillac W, Dhawan AR, Feng F, Esparza-Villa JU, Thuc Hien NT, Liem NQ, Coolen L, Nga PT (2017) Near-infrared emitting CdTeSe alloyed quantum dots: Raman scattering, photoluminescence and single-emitter optical properties, RSC Adv., 7: 47966-47974.

[2] Li L, Chen Y, Lu Q, Ji J, Shen Y, Xu M, Fei R, Yang G, Zhang K, Zhang J-R, Zhu J-J (2013) Electrochemiluminescence energy transfer-promoted ultrasensitive immunoassay using nearinfrared-emitting CdSeTe/CdS/ZnS quantum dots and gold nanorods, Scientific reports, 3: 01529.

[3] Bailey RE, Nie S (2003) Alloyed Semiconductor Quantum Dots: Tuning the Optical Properties without Changing the Particle Size, J. Am. Chem. Soc. , 125: 7100-7106.

[4] Wang R, Shang Y, Kanjanaboos P, Zhou W, Ning Z, Sargent EH (2016) Colloidal quantum dot ligand engineering for high performance solar cells, Energy Environ. Sci., 9: 1130-1143.

[5] Yu WW, Qu L, Guo W, Peng X (2003) Experimental Determination of the Extinction Coefficient of CdTe, CdSe, and CdS Nanocrystals, Chem. Mater., 15: 2854-2860.

[6] Xue J, Chen X, Liu S, Zheng F, He L, Li L, Zhu JJ (2015) Highly Enhanced Fluorescence of CdSeTe Quantum Dots Coated with Polyanilines via In-Situ Polymerization and Cell Imaging Application, ACS Appl. Mater. Interfaces, 7: 19126-19133.

[7] Zou H, Liu M, Zhou D, Zhang X, Liu Y, Yang B, Zhang H (2017) Employing CdSe $\mathrm{Te}_{1-\mathrm{x}}$ Alloyed Quantum Dots to Avoid the Temperature-Dependent Emission Shift of Light-Emitting Diodes, The Journal of Physical Chemistry C, 121: 5313-5323.

[8] Ponomarenko LA, Schedin F, Katsnelson MI, Yang R, Hill EW, Novoselov KS, Geim AK (2008) Chaotic Dirac Billiard in Graphene Quantum Dots, Science 320: 356-358.

[9] Li L-s, Yan X (2010) Colloidal Graphene Quantum Dots, J. Phys. Chem. Lett., 1: 2572-2576.

[10] Ritter KA, Lyding JW (2009) The influence of edge structure on the electronic properties of graphene quantum dots and nanoribbons, Nature materials, 8: 235-242. 
[11] Tetsuka H, Asahi R, Nagoya A, Okamoto K, Tajima I, Ohta R, Okamoto A (2012) Optically tunable amino-functionalized graphene quantum dots, Adv. Mater., 24: 5333-5338.

[12] Mahasin Alam Sk, Ananthanarayanan A, Huang L, Lim KH, Chen P (2014) Revealing the tunable photoluminescence properties of graphene quantum dots, J. Mater. Chem. C, 2: 6954-6960.

[13] Li L, Wu G, Yang G, Peng J, Zhao J, Zhu JJ (2013) Focusing on luminescent graphene quantum dots: current status and future perspectives, Nanoscale, 5: 4015-4039.

[14] Ozhukil Valappil M, K. Pillai V, Alwarappan S (2017) Spotlighting graphene quantum dots and beyond: Synthesis, properties and sensing applications, Applied Materials Today, 9: 350-371.

[15] Lin L, Rong M, Luo F, Chen D, Wang Y, Chen X (2014) Luminescent graphene quantum dots as new fluorescent materials for environmental and biological applications, TrAC, Trends Anal. Chem., 54: 83-102.

[16] Dai W, Lei Y, Xu M, Zhao P, Zhang Z, Zhou J (2017) Rare-Earth Free Self-Activated Graphene Quantum Dots and Copper-Cysteamine Phosphors for Enhanced White Light-Emitting-Diodes under Single Excitation, Scientific reports, 7: 12872.

[17] Zuo W, Tang L, Xiang J, Ji R, Luo L, Rogée L, Ping Lau S (2017) Functionalization of graphene quantum dots by fluorine: Preparation, properties, application, and their mechanisms, Appl. Phys. Lett., 110: 221901.

[18] Ju J, Liu W, Perlaki CM, Chen K, Feng C, Liu Q (2017) Sustained and Cost Effective Silver Substrate for Surface Enhanced Raman Spectroscopy Based Biosensing, Scientific reports, 7: 6917.

[19] Kwon W, Kim YH, Kim JH, Lee T, Do S, Park Y, Jeong MS, Lee TW, Rhee SW (2016) High Color-Purity Green, Orange, and Red Light-Emitting Diodes Based on Chemically Functionalized Graphene Quantum Dots, Scientific reports, 6: 24205.

[20] Kleinman SL, Frontiera RR, Henry AI, Dieringer JA, Van Duyne RP (2013) Creating, characterizing, and controlling chemistry with SERS hot spots, Physical chemistry chemical physics : PCCP, 15: 21-36.

[21] Nie S, Emory SR (1997) Probing Single Molecules and Single Nanoparticles by SurfaceEnhanced Raman Scattering, Science, 275: 1102-1106.

[22] Kneipp K, Wang Y, Kneipp H, Perelman LT, Itzkan I, Dasari RR, Feld MS (1997) Single Molecule Detection Using Surface-Enhanced Raman Scattering (SERS), Phys. Rev. Lett., 78: 1667-1670.

[23] Zhang W, Li C, Gao K, Lu F, Liu M, Li X, Zhang L, Mao D, Gao F, Huang L, Mei T, Zhao J (2018) Surface-enhanced Raman spectroscopy with Au-nanoparticle substrate fabricated by using femtosecond pulse, Nanotechnology, 29: 205301.

[24] Wu H, Luo Y, Hou C, Huo D, Zhou Y, Zou S, Zhao J, Lei Y (2019) Flexible bipyramid-AuNPs based SERS tape sensing strategy for detecting methyl parathion on vegetable and fruit surface, Sensors Actuators B: Chem., 285: 123-128.

[25] Chang T-H, Chang Y-C, Chen C-M, Chuang K-W, Chou C-M (2019) A facile method to directly deposit the large-scale Ag nanoparticles on a silicon substrate for sensitive, uniform, reproducible and stable SERS substrate, J. Alloys Compd., 782: 887-892.

[26] Wang S, Wang Z, Tang N, Liu C, He S, Liu B, Qu H, Duan X, Pang W, Wang Y (2019) Hierarchical assembly of gold nanorod stripe patterns for sensing and cells alignment, Nanotechnology, 30: 175302.

[27] Milekhin AG, Sveshnikova LL, Duda TA, Surovtsev NV, Adichtchev SV, Zahn DRT (2009) Surface enhanced Raman scattering by CdS quantum dots, JETP Letters, 88: 799-801.

[28] Hugall JT, Baumberg JJ, Mahajan S (2009) Surface-enhanced Raman spectroscopy of CdSe quantum dots on nanostructured plasmonic surfaces, Appl. Phys. Lett., 95: 141111.

[29] Lee Y-b, Ho Lee S, Lee S, Lee H, Kim J, Joo J (2013) Surface enhanced Raman scattering effect of CdSe/ZnS quantum dots hybridized with Au nanowire, Appl. Phys. Lett., 102: 033109.

[30] Sheremet E, Milekhin AG, Rodriguez RD, Weiss T, Nesterov M, Rodyakina EE, Gordan OD, Sveshnikova LL, Duda TA, Gridchin VA, Dzhagan VM, Hietschold M, Zahn DRT (2015) Surface- and tip-enhanced resonant Raman scattering from CdSe nanocrystals, Phys. Chem. Chem. Phys. , 17: 21198-21203.

[31] Stadelmann K, Elizabeth A, Martín Sabanés N, Domke KF (2017) The SERS signature of PbS quantum dot oxidation, Vib. Spectrosc, 91: 157-162.

[32] Fazio E, Neri F, Savasta S, Spadaro S, Trusso S (2012) Surface-enhanced Raman scattering of $\mathrm{SnO}_{2}$ bulk material and colloidal solutions, Physical Review B, 85 . 
[33] Dogan I, Gresback R, Nozaki T, van de Sanden MC (2016) Analysis of temporal evolution of quantum dot surface chemistry by surface-enhanced Raman scattering, Scientific reports, 6: 29508.

[34] Sigle DO, Hugall JT, Ithurria S, Dubertret B, Baumberg JJ (2014) Probing confined phonon modes in individual CdSe nanoplatelets using surface-enhanced Raman scattering, Physical review letters, 113: 087402.

[35] Vo-Dinh T, Hiromoto MYK, Begun GM, Moody RL (1984) Surface-enhanced Raman spectrometry for trace organic analysis, Anal. Chem., 56: 1667-1670.

[36] Frederich H, Wen F, Laverdant J, Coolen L, Schwob C, Maître A (2011) Isotropic broadband absorption by a macroscopic self-organized plasmonic crystal, OExpr, 19: 24424-24433.

[37] Yi Z, Niu G, Luo J, Kang X, Yao W, Zhang W, Yi Y, Yi Y, Ye X, Duan T, Tang Y (2016) Ordered array of Ag semishells on different diameter monolayer polystyrene colloidal crystals: An ultrasensitive and reproducible SERS substrate, Scientific reports, 6: 32314.

[38] Wu MC, Lin MP, Chen SW, Lee PH, Li JH, Su WF (2014) Surface-enhanced Raman scattering substrate based on a Ag coated monolayer array of $\mathrm{SiO}_{2}$ spheres for organic dye detection, RSC Advances, 4: 10043.

[39] Lin W-C, Liao L-S, Chen Y-H, Chang H-C, Tsai DP, Chiang H-P (2010) Size Dependence of Nanoparticle-SERS Enhancement from Silver Film over Nanosphere (AgFON) Substrate, Plasmonics, 6: 201-206.

[40] Ngo HT, Wang HN, Fales AM, Vo-Dinh T (2013) Label-free DNA biosensor based on SERS Molecular Sentinel on Nanowave chip, Analytical chemistry, 85: 6378-6383.

[41] Campos AR, Gao Z, Blaber MG, Huang R, Schatz GC, Van Duyne RP, Haynes CL (2016) Surface-Enhanced Raman Spectroscopy Detection of Ricin B Chain in Human Blood, The Journal of Physical Chemistry C, 120: 20961-20969.

[42] Zhang X, Young MA, Lyandres O, Duyne RPV (2005) Rapid Detection of an Anthrax Biomarker by Surface-Enhanced Raman Spectroscopy, J. AM. CHEM. SOC., 127: 4484-4489.

[43] Masango SS, Hackler RA, Henry A-I, McAnally MO, Schatz GC, Stair PC, Van Duyne RP (2016) Probing the Chemistry of Alumina Atomic Layer Deposition Using Operando Surface-Enhanced Raman Spectroscopy, The Journal of Physical Chemistry C, 120: 3822-3833.

[44] Frederich H, Wen F, Laverdant J, de Marcillac WD, Schwob C, Coolen L, Maître A (2014) Determination of the Surface Plasmon Polariton Extraction Efficiency from a Self-Assembled Plasmonic Crystal, Plasmonics, 9: 917-924.

[45] Inoue A, Sugimoto H, Fujii M (2107) Photoluminescence Enhancement of Silicon Quantum Dot Monolayer by Double Resonance Plasmonic Substrate, J. Phys. Chem. C, 121: 11609-11615.

[46] Stober W, Fink A, Bohn E (1968) Controlled Growth of Monodisperse Silica Spheres in the Micron Size Range., J. Colloid Interface Sci., 26: 62-69.

[47] Milczarek G, Motylenko M, Modrzejewska-Sikorska A, Klapiszewski Ł, Wysokowski M, Bazhenov VV, Piasecki A, Konował E, Ehrlich H, Jesionowski T (2014) Deposition of silver nanoparticles on organically-modified silica in the presence of lignosulfonate, RSC Adv., 4: 52476-52484.

[48] Dong Y, Shao J, Chen C, Li H, Wang R, Chi Y, Lin X, Chen G (2012) Blue luminescent graphene quantum dots and graphene oxide prepared by tuning the carbonization degree of citric acid, Carbon, 50: 4738-4743.

[49] Wang L, Wang Y, Xu T, Liao H, Yao C, Liu Y, Li Z, Chen Z, Pan D, Sun L, Wu M (2014) Gramscale synthesis of single-crystalline graphene quantum dots with superior optical properties, Nature communications, 5: 5357.

[50] Qu D, Zheng M, Zhang L, Zhao H, Xie Z, Jing X, Haddad RE, Fan H, Sun Z (2014) Formation mechanism and optimization of highly luminescent $\mathrm{N}$-doped graphene quantum dots, Scientific reports, 4: 5294.

[51] Laverdant J, Buil S, Bérini B, Quélin X (2008) Polarization dependent near-field speckle of random gold films, Physical Review B, 77.

[52] Buil S, Laverdant J, Berini B, Maso P, Hermier J-P, Quélin aX (2012) FDTD simulations of localization and enhancements on fractal plasmonics nanostructures, OExpr, 20: 11968-11975.

[53] Neto ESF, da Silva SW, Morais PC, Vasilevskiy MI, Pereira-da-Silva MA, Dantas NO (2011) Resonant Raman scattering in $\mathrm{CdS}_{\mathrm{x}} \mathrm{Se}_{1-\mathrm{x}}$ nanocrystals: effects of phonon confinement, composition, and elastic strain, Journal of Raman Spectroscopy, 42: 1660-1669. 
[54] Bragas AV, Aku-Leh C, Merlin R (2006) Raman and ultrafast optical spectroscopy of acoustic phonons inCdTe ${ }_{0.68} \mathrm{Se}_{0.32}$ quantum dots, Physical Review B, 73: 125305-125309.

[55] Beams R, Cancado LG, Novotny L (2011) Low temperature raman study of the electron coherence length near graphene edges, Nano letters, 11: 1177-1181.

[56] Tuinstra F, Koenig JL (1970) Raman Spectrum of Graphite, The Journal of Chemical Physics, 53: 1126.

[57] Ferrari AC, Meyer JC, Scardaci V, Casiraghi C, Lazzeri M, Mauri F, Piscanec S, Jiang D, Novoselov KS, Roth S, Geim AK (2006) Raman spectrum of graphene and graphene layers, Physical review letters, 97: 187401.

[58] Vion C, Spinicelli P, Coolen L, Schwob C, Frigerio J-M, Hermier J-P, Maître A (2010) Controlled modification of single colloidal CdSe/ZnS nanocrystal fluorescence through interactions with a gold surface, OExpr, 18: 7440-7455.

[59] Fang Y, Seong N-H, Dlott DD (2008) Measurement of the Distribution of Site Enhancements in Surface-Enhanced Raman Scattering, SCIENCE, 321: 388-392.

[60] Lethiec C, Binard G, Popescu T, Frederich H, Phan Ngoc H, Yraola E, Schwob C, Charra F, Coolen L, Douillard L, Maître A (2016) Plasmonics of Opal Surface: A Combined Near- and FarField Approach, The Journal of Physical Chemistry C, 120: 19308-19315. 